\title{
SBR sisteminin antibiyotik (tetrasiklin/klortetrasiklin) ve ağrı kesici (parasetamol) etkisinde nitrifikasyon ve denitrifikasyon performansının belirlenmesi
}

\author{
Determination of nitrification and denitrification performance in antibiotic \\ (tetracycline/chlortetracycline) and pain relief (paracetamol) effect in the SBR
} system

\author{
Aytekin Çelik ${ }^{1, *}$ \\ ${ }^{1}$ Firat Üniversitesi, Çevre Mühendisliği Bölümü, 23000, Elazı̆̆, Türkiye
}

\begin{abstract}
Özet
Antibiyotikler ve ağrı kesiciler diğer farmasotikler gibi sucul ortamda biyolojik yaşama olumsuz yönde etki etmektedir. Bu amaçla bu tür kirleticilerin sucul veya bulundukları ortamdan giderilmesi önem arz etmektedir. $\mathrm{Bu}$ çalışmada, tetrasiklin/parasetamol ve klortetrasiklin /parasetamol ikilisinin SBR prosesine eş zamanlı verilmesi ile nitrifikasyon ve denitrifikasyon üzerine ne gibi etkileri olduğu araştırılmıştır. Çalışmada iki ayrı reaktör kullanılmıştır, ve toplam da 9 periyot uygulanarak yürütülmüştür. Tetrasiklin/parasetamol ve klortetrasiklin /parasetamol varlığında nitrifikasyon en çok 6. şartta etkilenmiş olup, nitrifikasyon verimi $\% 33$ civarında tespit edilmiştir. Aynı şekilde 6 . şarttaki $\mathrm{NO}_{2}-\mathrm{N}$ birikimi de diğer şartlara göre çok yüksek olup, $8.5 \mathrm{mg} / \mathrm{L}$ civarında gözlenmiştir. Tetrasiklin/parasetamol ve klortetrasiklin/ parasetamol varlığında denitrifikasyon ise en çok 9. şartta etkilenmiş olup, bu şartta \%1 civarında denitrifikasyon verimi elde edilmiştir. Sonuç olarak, Tetrasiklin/ parasetamol ve klortetrasiklin/parasetamol ikilisi altındaki nitrifikasyon ve denitrifikasyon verimi, düşük hidrolik alıkonma sürelerinde ve $100 \mathrm{mg} / \mathrm{L}$ üzeri TC/PCT ve CTC/PCT konsantrasyonlarında nitrifiye ve denitrifiye bakterilerine olumsuz yönde etki ettiği belirlenmiştir.
\end{abstract}

Anahtar kelimeler: Denitrifikasyon, Nitrifikasyon, Parasetamol, Tetrasiklin

\section{Giriş}

Yaygın bir analjezik ve antipiretik ilaç olan PCT [1], birçok ilacın hammaddesi olarak yaygın bir kullanıma sahiptir. Başka bir deyişle, PCT (N-asetil-4-amino-fenol), yetişkinlerde ve çocuklarda baş ağrısı, artralji, kanserden kronik ağrı ve ateş tedavisinde yaygın olarak kullanılan bir asillenmiş aromatik amiddir [2]. İyi bir ağrı kesici olmasının yanı sıra, kahverengi ağaç yılanlarını kontrol etmek ve insanlarda hepetoksisiteye neden olmak için belirli bir miktar PCT de kullanılabilir. Çevrede çok sayıda organizma olduğundan ve her organizmanın farklı hassasiyetleri olduğundan, farmasötikler çevre için risk faktörleri olarak nitelendirilebilir [1].

\begin{abstract}
Antibiotics and painkillers, like other pharmaceutics, negatively affect biological life in the aquatic environment. For this purpose, it is important to remove such pollutants from their aquatic or environment. In this study, the effects of tetracycline/paracetamol and chlortet racycline / paracetamol on nitrification and denitrification were investigated by simultaneously giving to the SBR process. Two separate reactors were used in the study and a total of 9 periods were applied. In the presence of tetracycline/paracetamol and chlortetracycline/ para cetamol, nitrification was most affected under the 6th condition and nitrification efficiency was determined around $33 \%$. Likewise, the $\mathrm{NO}_{2}-\mathrm{N}$ accumulation in the 6 th condition is very high compared to other conditions and has been observed around $8.5 \mathrm{mg} / \mathrm{L}$. Denitrification in the presence of tetracycline/paracetamol and chlortetracycline/ paracetamol was most affected in the 9th condition and denitrification efficiency of around $1 \%$ was achieved in this condition. As a result, nitrification and denitrification efficiency under tetracycline/paracetamol and chlortet racycline/paracetamol were found to adversely affect nitrifiye and denitrifiye bacteria during low hydraulic detention times and concentrations of TC/PCT and CTC/PCT above $100 \mathrm{mg} / \mathrm{L}$
\end{abstract}

Keywords: Denitrification, Nitrification, Paracetamol, Tetracycline

Geniş spektrumlu bir antibakteriyel ilaç olarak tetrasiklin (TC), antibakteriyel ve düşük maliyetli avantajları nedeniyle insan ve hayvan hastalıklarının önlenmesi ve tedavisinde yaygın olarak kullanılmaktadır [3]. Bununla birlikte, sadece insan veya hayvan vücutlarına alınan TC miktarı az miktarda metabolize edilir ve ayrışır ve kalan TC tortuları, ham ilaçlar veya metabolitler olarak su ortamına salınır ve sürekli olarak su kütlesinde birikir [4, 5].

Kullanım ömrünü tamamlamış antibiyotiklerin çöp kutusu, tuvalet veya lavabolara dökülmesiyle, ağız yoluyla alınan antibiyotiklerin ise büyük kısmının bağırsaklarda emilmeden doğrudan dışkı ile kanalizasyona, buradan da yeraltı ve yerüstü sularına karışması, sucul veya karıştığı ortam canlılarının yaşam kalitesini tehdit etmektedir.

\footnotetext{
* Sorumlu yazar / Corresponding author, e-posta / e-mail: aytekincelik@ firat.edu.tr (A.Celik)

Geliş / Recieved: 16.09.2020 Kabul / Accepted: 25.06.2021 Yayımlanma / Published: 27.07.2021

doi: $10.28948 /$ ngmuh.795716
} 
İlaveten, günümüzde antibiyotikler, tavuk ve balık başta olmak üzere, hayvanların büyümelerinin hızlandırılmasında da kullanılmaktadır [6]. Örneğin; Sülfonamidler, biyolojik bozulmaya dirençlidirler ve uzun süre doğada kalabilirler. Topraktaki emilimlerinin düşük olması sebebiyle de yeraltı sularına veya diğer kaynaklara hızlıca ulaşabilirler. Çevreye salındığında sudaki çözünürlüğünün yüksek olması sebebiyle de kolayca yüzey sularına ulaşabilirler [7].

Tetrasiklinler (TC) birçok bakteriyal enfeksiyonun tedavisi için önemli farmasötik antibiyotikler olup, hayvan hastalıklarını tedavi etmek ve hayvanların büyümelerini hızlandırmak için hayvansal gıdalara eklenebilmektedir. Hayvansal dışkıların bitkiler için gübre olarak kullanılması nedeniyle de toprağa veya su ortamına karışabilmekte, bu da antibiyotiğe dirençli bakterilere ve TC'den daha yüksek kirletici özelliğindeki yeni kirletici bileşikler oluşumuna neden olabilmektedir [8].

Nitrifikasyon, amonyağın nitrite, nitritin de nitrata aerobik oksidasyonu ile olan azot $(\mathrm{N})$ döngü işlemidir. [9] Nitrat $\left(\mathrm{NO}_{3}{ }^{-}\right)$en yaygın su kirleticilerinden biridir ve dünyanın birçok bölgesinde ciddi bir çevresel kaygıdır[10]. Son y1llarda, Amerikan ve Avrupa nehirlerindeki nitrat konsantrasyonları önemli ölçüde artmış ve 100 yıl öncesine göre 15 kat daha yüksek konsantrasyonlara ulaşmıştır [11]. Biyolojik denitrifikasyon, sınırlı miktarda enerji ve kimyasallar gerektirdiği için iyon değişimi, adsorpsiyon ve ters ozmoz gibi fiziko kimyasal işlemlerden daha uygun maliyetli ve çevre dostu bir nitrat oluşturma yöntemidir. Diğer yandan, denitrifikasyon mikroorganizmaları kirlenmiş suyun fiziksel ve kimyasal parametrelerine karşı çok hassastır. Bununla birlikte, biyolojik denitrifikasyon, nitratça zengin çeşitli endüstriyel atıksuların arıtılması için yaygın olarak kullanılmaktadır [12].

Nitrifikasyonun ilk kademesinde AOB'ler Eşitlik (1.1)'e göre $\mathrm{NH}_{4}{ }^{+}$ü $\mathrm{NO}_{2}$ 'ye, İkinci kademede ise NOB'ler nitrit oksidoredüktaz enzimi yardımıyla oksijen varlığında $\mathrm{NO}_{2}$ 'nin $\mathrm{NO}_{3}$ 'e (Eşitlik 1.2) oksidasyonunu sağlarlar [13];

$\mathrm{NH}_{4}^{+}+\mathrm{O}_{2}+\mathrm{H}^{+}+2 \mathrm{e}^{-}>\mathrm{NO}_{2}^{-}+\mathrm{H}_{2} \mathrm{O}$

$\mathrm{NO}_{2}^{-}+\mathrm{H}_{2} \mathrm{O}>\mathrm{NO}_{3}{ }^{-}+2 \mathrm{H}^{+}+2 \mathrm{e}^{-}$

Ardışık kesikli reaktör (SBR), bir dizi doldurma ve çekme çevrimi üzerinde çalışan, aktif çamur esaslı atık su arıtma sistemlerine verilen addır. Bir SBR'de yer alan birim işlemler, geleneksel aktif çamur sistemlerine eşdeğerdir. Bu nedenle havalandırma ve sedimantasyon-berraklaştırma yapılır. Sistemler arasındaki fark, geleneksel sistemlerde, bu iki işlemin iki farklı tankta gerçekleşmesi, SBR sistemlerinde ise aynı tankta sırayla gerçekleşmeleridir[14]. $\mathrm{Bu}$ kesikli sistemlerin avantajlarından biri, kirletici konsantrasyonlarının sürekli değişimleri için kolaylıkla uyarlanabilmeleridir [15].

Ardışık Kesikli Reaktör (SBR), organik karbon ve nütrient gideriminde en yaygın kullanılan reaktördür. SBR'de uygulanan kolay ve esnek işletimde \%90'dan fazla toplam azot giderimi, \%25 havalandırma maliyeti tasarrufu, yüksek çamur yaşı ile az, spesifik ve iyi çökelen çamur oluşumu elde edilir [16].
TC ve PCT'nin özellikleri ve çevresel su ortamında etkileri yukarıda ifade edilmiştir. Literatürde TC/PCT ve CTC/PCT ikililerinin nitrifiye ve denitrifiye bakterileri üzerine toksik etki oluşturma hakkında çalışma bulunmamaktadır. Malumdur ki bu iki ilaç türü sucul çevrede birlikte bulunma durumları çok geneldir.

$\mathrm{Bu}$ çalışmada aerobik/anaerobik SBR reaktörlerinde TC/PCT ve CTC/PCT'nin nitrifiye ve denitrifiye bakterileri üzerine etkisi araştırılmıştır. Bu kapsamda havalandırma süresi, hidrolik bekleme zamanı, çözünmüş oksijen konsantrasyonu, TC, PCT ve CTC konsantrasyonları ve sisteme anaerobik fazda eklenen asetat miktarı gibi bazı parametreler açısından sistemin azot giderim performansı araştırılmıştır.

\section{Materyal ve metot}

\section{$2.1 S B R$}

Çalışmada kullandığımız SBR reaktörü Şekil 1'de gösterilmiştir. Bu reaktör alışma devresi hariç toplamda 93 gün işletilmiştir. Şekilden de anlaşıldığı üzere 1 numara sistemi besleyen pompay1, 2 numara SBR reaktörünü, 3 numara hava pompasını, 4 numara zaman ayarlayıcıyı, 5 numara ise çıkış reaktörünü göstermektedir. Ayrıca kullanılan reaktör hacmi $1 \mathrm{~L}$ dir.

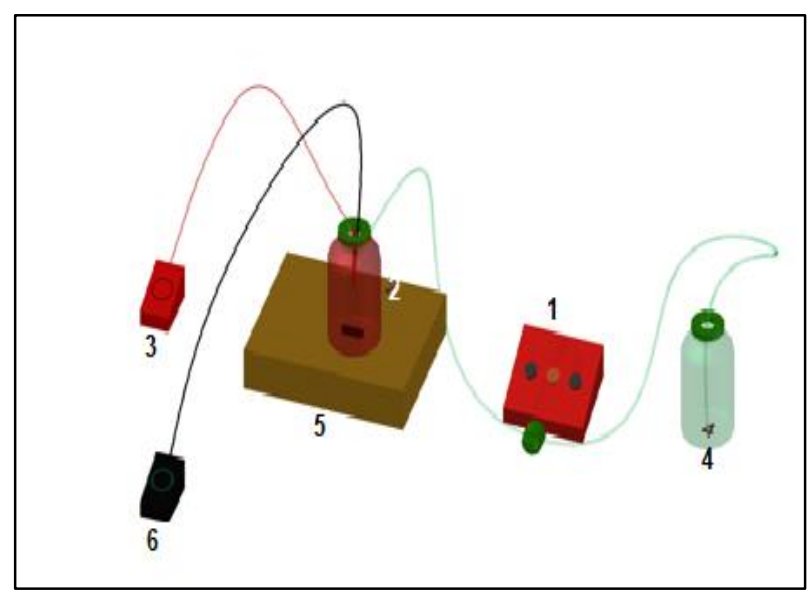

Şekil 1. SBR sistemi

\subsection{Adaptasyon süreci ve işletme şartlart}

Hem nitrifikasyon hem de denitrifikasyon sistemi olan atıksu arıtma tesisinden alınan çamur reaktör hacminin 10'da 1'i olacak şekilde reaktöre ilave edilmiştir. Başlangıçta nitrifikasyon/denitrifikasyon bakterilerin sisteme uyumu için sentetik atıksu hazırlanıp oksijen verilip/kesilmesi ile yaklaşık 10-15 gün bu şekilde çalışılmıştır. Daha sonra çalışma periyotları birer birer uygulanarak tetrasiklinler ve parastemolun aynı reaktörde nitrifikasyon ve denitrifikasyon bakterileri ile giderim performansı bir birlerine kıyasla incelenmiştir. $\mathrm{Bu}$ çalışmada reaktör toplamda 93 gün işletilmiş olup, kısa periyot sürelerinin sistem üzerinde etkileri de ayrıca araştırılmıştır. Ayrıca $\mathrm{NO}_{3}{ }^{-}, \mathrm{NO}_{2}{ }^{-}, \mathrm{NH}_{4}{ }^{+}$ analizleri Shimadzu marka iyon chromatograph cihazında yapılmıştır. Ayrıca Tablo 1' de işletme şartları belirtilmiştir. 
Tablo 1. İşletim şartları

\begin{tabular}{|c|c|c|c|c|c|c|c|}
\hline Periyot & $\begin{array}{l}\text { Tetrasiklin/Klortetrasiklin } \\
\text { Konsantrasyonu (mg/L) }\end{array}$ & $\begin{array}{c}\text { Parasetamol } \\
\text { Konsantrasyonu } \\
(\mathrm{mg} / \mathrm{L})\end{array}$ & $\begin{array}{l}\text { Zaman } \\
\text { (Gün) }\end{array}$ & $\begin{array}{c}\text { Aerobik } \\
\text { Bekleme } \\
\text { Zamanı (st) }\end{array}$ & $\begin{array}{c}\text { Anoksik } \\
\text { Bekleme } \\
\text { Zamanı (st) }\end{array}$ & $\begin{array}{l}\text { Sodyum } \\
\text { Asetat (gr) }\end{array}$ & $\begin{array}{l}\text { Çözünmüş } \\
\text { Oksijen }(\mathrm{mg} / \mathrm{L})\end{array}$ \\
\hline $\mathrm{P} 1$ & $0.4-0.5$ & $0.5-0.55$ & $18-33$ & 9 & 14 & 0.14 & $1-2$ \\
\hline $\mathrm{P} 2$ & “ & “ & $33-40$ & 14 & 9 & 0.3 & $4-5$ \\
\hline $\mathrm{P} 3$ & “ & “ & $40-58$ & 9 & 14 & “ & $4-5$ \\
\hline $\mathrm{P} 4$ & $1-1.1$ & $1.95-2.1$ & $58-68$ & 14 & 9 & 0.6 & “ \\
\hline P5 & $0.95-1$ & $1.95-2.0$ & $68-77$ & 9 & 14 & “ & “ \\
\hline P6 & $0.9-1$ & 1.9-2 & $77-83$ & 3 & 5 & “ & “ \\
\hline P7 & “ & $4.9-5$ & $83-88$ & 14 & 9 & “ & “ \\
\hline P8 & Beslenmedi & $\begin{array}{l}100-110 \mathrm{mg} / \mathrm{L} \\
\text { (Aerobik fazla) }\end{array}$ & $88-98$ & 14 & 9 & 0.04 & “ \\
\hline P9 & Beslenmedi & $\begin{array}{c}500-515 \mathrm{mg} / \mathrm{L} \\
\text { (Anaerobik fazla) }\end{array}$ & $98-101$ & 12 & 11 & 0.04 & “ \\
\hline
\end{tabular}

\subsection{Kimyasallar}

Tetrasiklin hidroklorid (CAS No. 2058-46-0), klortetrasiklin (CAS No. 64-72-2) Applichem and SigmaAldrich firmasından satın alındı. Parasetamol ise (CAS No. AC102332500) Across Organics firmasından satın alındı. Diğer kimyasallar, $\mathrm{NaCl}, \mathrm{Na}_{2} \mathrm{SO}_{4}, \mathrm{NaNO}_{3}$, ise ACS markalıdır.

\subsection{Sentetik atıksu içeriğ $i$}

Sentetik atıksu içeriği litre başına aşağıdaki gibidir: $0.115 \mathrm{~g} \quad\left(\mathrm{NH}_{4} \mathrm{Cl}\right), \quad 0.50 \mathrm{~g} \quad \mathrm{NaHCO}_{3}, \quad 0.13 \mathrm{~g} \quad \mathrm{KH}_{2} \mathrm{PO}_{4}, \quad 0.1 \mathrm{~g}$ $\mathrm{MgSO}_{4} .7 \mathrm{H}_{2} \mathrm{O}, 0.001 \mathrm{~g} \mathrm{CaCl}_{2} \mathrm{X} 2 \mathrm{H}_{2} \mathrm{O}, 0.001 \mathrm{~g} \mathrm{FeSO}_{4} \mathrm{X} 7 \mathrm{H}_{2} \mathrm{O}$, Farklı miktarlarda $(0.14,0.30$ ve $0.60 \mathrm{~g}) \mathrm{CH}_{3} \mathrm{COONaxH}_{2} \mathrm{O}$ ve $2 \mathrm{ml}$ eser mineral çözeltisi. Eser mineral çözeltisi litre başına: $100 \mathrm{mg} \mathrm{ZnSO}_{4} .7 \mathrm{H}_{2} \mathrm{O}$, 30mg $\mathrm{MnCl}_{2} .4 \mathrm{H}_{2} \mathrm{O}$, 300mg $\mathrm{H}_{3} \mathrm{BO}_{3}$, 200mg $\mathrm{CoCl}_{2} .6 \mathrm{H}_{2} \mathrm{O}, 10 \mathrm{mg} \mathrm{CuCl}_{2} .2 \mathrm{H}_{2} \mathrm{O}, 10 \mathrm{mg}$ $\mathrm{NiCl}_{2} \cdot 6 \mathrm{H}_{2} \mathrm{O}$ olarak hazırlanmıştır.

\section{Bulgular ve tartışma}

Tetrasiklin/Parasetamol ve klortetrasiklin/Parasetamolun SBR reaktöründeki nitrifikasyon ve denitrifikasyon üzerine etkileri aşağıda tartışılmıştır. Çalışma toplamda 9 periyottan oluşmaktadır.

\subsection{Tetrasiklin/Parasetamol klortetrasiklin/parasetamol ikilisinin nitrifikasyon üzerine etkisi}

Şekil 2a Tetrasiklin/Parasetamol ve Klortetrasiklin/ Parasetamol ikilisinin nitrifikasyon üzerine etkisini göstermektedir. $\mathrm{Bu}$ çalışmada toplamda 9 periyot uygulanmıştır. P1 de TC/PCT ve CTC/PCT ikilisinin sebep olduğu nitrifikasyon verimi sirasiyla \%50.7ve \%45.6 olmuştur. CTC/PCT' nin nitirifikasyon üzerine daha fazla etki ettiği P1 de açıkça görülmüştür. Ayrıca P1 de nitrifikasyon verimlerinin düşük olmalarının sebebi de çözünmüş oksijenin bu şartta $1-2 \mathrm{mg} / \mathrm{L} \mathrm{mg} / \mathrm{L}$ arasında olmasıdır. P2' de ise nitrifkasyon verimi artarak TC/PCT ve CTC/PCT ikilisi için sırasıyla \%93.5 ve \%94.9 olmuştur. Yapılan bir çalışmada, domuz çiftliği atık suyunda pilot ölçekli SBR prosesi kullanılmış ve 600 ile 1600 mg/L NH4 konsantrasyonunda \%80 üzeri nitrifikasyon ve \%90 üzeri denitrifikasyon verimi sağlandığı rapor edilmiştir [17]. P3'de de nitrifikasyon verimi artarak TC/PCT ve CTC/PCT için
\%98.82 olmuştur. Bu ilk 3 periyotta TC/PCT ve CTC/PCT besleme konsantrasyonu ikili için $0.5 / 0.5 \mathrm{mg} / \mathrm{L}$ olmuştur. $\mathrm{Bu}$ ilk üç periyot incelendiğinde genel olarak $0.5 \mathrm{mg} / \mathrm{L}$ 'lik TC/PCT ve CTC/PCT'nin nitrifikasyon üzerine önemli tesiri olmamıştır. P4'te TC, PCT, CTC konsantrasyonları 2 katına çıkartılarak sırasıyla, 1.2 ve $1 \mathrm{mg} / \mathrm{L}$ 'e yükseltilmiştir. TC, CTC ve PCT konsantrasyonu 2 katına çıkartılmasına rağmen bu periyotta nitrifikasyona önemli ölçüde tesir etmediği görülmüştür. P5'de nitrifikasyon verimi biraz düşmüştür. $\mathrm{Bu}$ duruma en büyük sebebin hidrolik bekleme süresinin bir önceki şarta göre daha düşük olmasıdır. P5'te elde edilen nitrifikasyon verimi TC/PCT etkisinde \%86.2 ve CTC/PCT etkisinde ise \%70.5 olarak elde edilmiștir. Bu şartta da nitrifikasyon için CTC'nin TC'den daha etkili olduğu bir kez daha anlaşılmıştır. P6'da hidrolik bekleme süresi 3 saate düşürülerek nitrifikasyon veriminde büyük bir düşüş yaşanmıştır. $\mathrm{Bu}$ şartta elde edilen nitrifikasyon verimi yaklaşık \%33 olmuştur. Dikkat çeken diğer bir husus da, TC/PCT ve CTC/PCT etkisindeki nitrfikasyon verimlerinin aynı olmasıdır. P7'de Parasetamol 5mg/L çıkarılmasına rağmen nitrifikasyon verimi TC/PCT ve CTC/PCT etkisinde \%95.2 olarak elde edilmiştir. $\mathrm{Bu}$ şartta TC ve CTC sabit tutulmuştur. P8'de Parasetamol konsantrasyonu 100 mg/L'e çıkartılmış olup, nitrifikasyon verimi de önemli derecede etkilenmeyerek \%94.7 olarak elde edilmiştir. P9'da anoksik fazda parecetemol $500 \mathrm{mg} / \mathrm{L}$ civarında beslenmiş olup nitrifkasyon verimi TC/PCT ve CTC/PCT etkisinde \%36 civarında elde edilmiştir. Parasetamol'ün anaerobik fazda beslenmesi nitrifkasyonun tamamen bitmesini engellemiștir.

Şekil 2b TC/PCT ve CTC/PCT ikilisinin nitrifikasyonda oluşan $\mathrm{NO}_{2}-\mathrm{N}$ konsantrasyonunu gösteriyor. Şekil incelendiğinde TC/PCT etkisindeki nitrit oluşumu CTC/PCT etkisindekinden daha fazla olmuştur. P1 de TC/PCT ve CTC/PCT etkisindeki nitrit konsantrasyonları sırasıyla, 1.77 ve $0.88 \mathrm{mg} / \mathrm{L}$ olmuştur. P1 de nitritin yüksek olması düşük çözünmüş oksijenden kaynaklanmıştır. P2 de nitrit oluşumu giderek azalmış olup, TC/PCT ve CTC/PCT için sırasıyla, 1.17 ve $0.178 \mathrm{mg} / \mathrm{L}$ olmuştur. $\mathrm{Bu}$ periyotta çözünmüş oksijen konsantrasyonu $4-5 \mathrm{mg} / \mathrm{L}$ arasına yükseltilmiştir. P3, P4 ve P5 de nitrit oluşumu stabilleşmiş, TC/PCT ve CTC/PCT için sırasıyla, $0.17,0.19$ ve 0.6 ve 0.06 olmuştur. P6 da aerobik hidrolik bekleme süresi 3 saate 


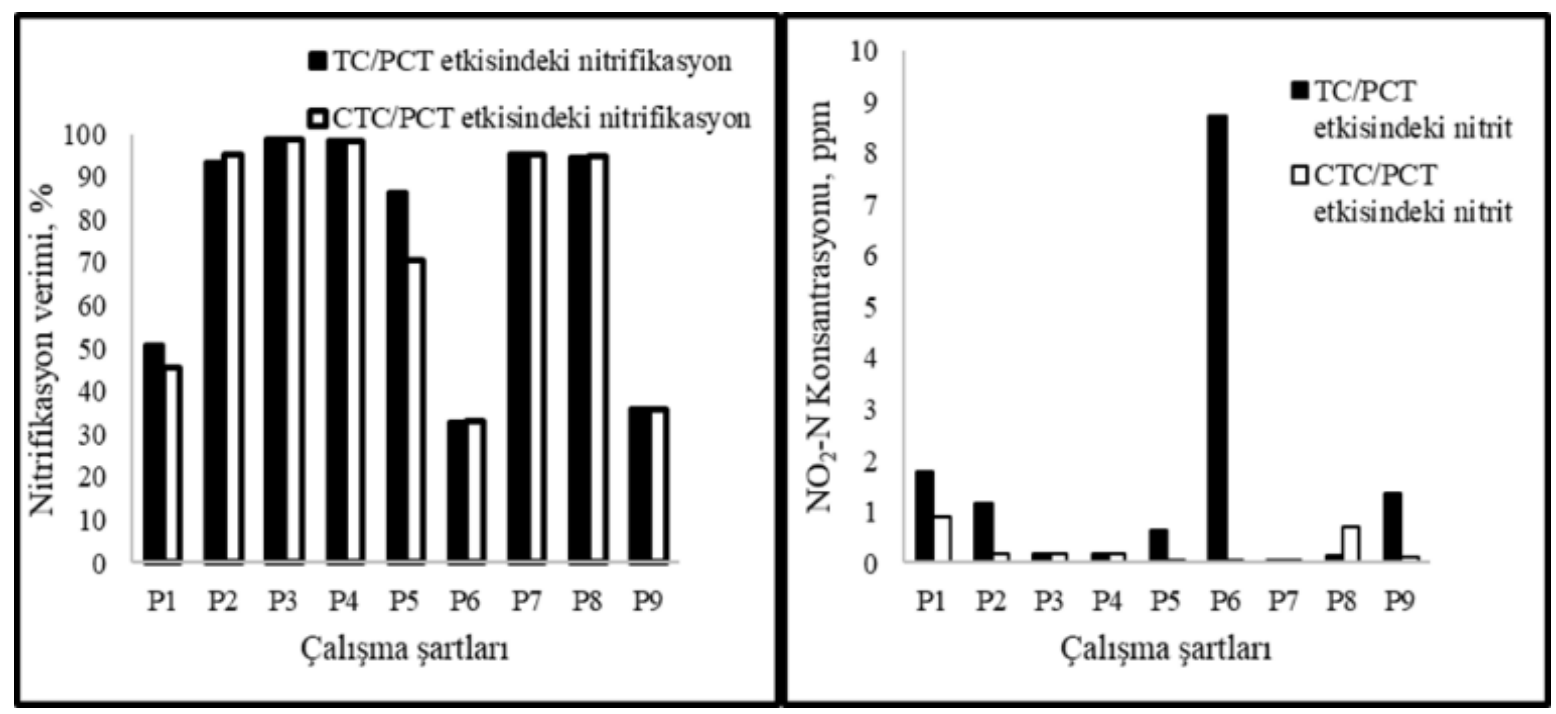

(a)

(b)

Şekil 2.Tetrasiklin/Parasetamol ve Klortetrasiklin/Parasetamol ikilisinin (a) nitrifikasyon, (b)nitrit oluşumu üzerine etkisi

düşürüldüğünde TC/PCT ve CTC/PCT etkisinde nitrit oluşumu sırasıyla 8.7 ve $0.014 \mathrm{mg} / \mathrm{L}$ olmuştur. Bu periyotta TC/PCT etkisindeki nitrit oluşumu nitriti nitrata çeviren bakterilerin TC'ye karşı daha hassas olduğunun göstergesi olmuştur. P7 ve P8 deki TC/PCT ve CTC/PCT etkisindeki nitrit oluşumu sırasıyla, 0.018 ve 0.16 ve $0.7 \mathrm{mg} / \mathrm{L}$ olmuştur. $\mathrm{P} 9 \mathrm{da}$ ise bu oran 1.35 ve $0.125 \mathrm{mg} / \mathrm{L}$ olmuştur. Şekil genel olarak incelendiğinde TC, CTC ve PCT konsantrasyonlarının artması nitrit oluşumunu önemli derecede etkilemediğini göstermiştir.

\subsection{Tetrasiklin/Parasetamol ve klortetrasiklin/ Parasetamol ikilisinin denitrifikasyon üzerine etkisi}

Şekil 3 TC/PCT ve CTC/PCT ikilisinin denitrifikasyon üzerine etkisini göstermektedir. Bu çalışmada toplamda 9 periyot uygulanmıştır. P1 de TC/PCT ve CTC/PCT ikilisinin sebep olduğu denitrifikasyon verimi sırasıyla \% 89.45 ve $\% 88.5$ olmuştur. CTC/PCT'nin denitrifikasyon üzerine daha fazla etki ettiği P1' de görülmüştür. Ayrıca P1' de nitrifikasyon verimlerinin düşük olmalarının sebebi de anaerobik fazda verilen sodyum asetatın $0.14 \mathrm{gr}$ olmasıdır. P2 de ise denitrifkasyon verimi artarak TC/PCT ve CTC/PCT ikilisi için \%92.6 olmuştur.

P3'te de denitrifikasyon verimi artarak TC/PCT ve CTC/PCT \%96.9 olmuştur. Bu ilk 3 periyotta TC/PCT ve CTC/PCT besleme konsantrasyonu ikili için 0.5/0.5 mg/L olmuştur. Bu ilk üç periyot incelendiğinde genel olarak 0.5 $\mathrm{mg} / \mathrm{L}$ lik TC/PCT ve CTC/PCT'nin denitrifikasyon üzerine önemli tesiri olmamıştır. P4'te TC, CTC ve PCT konsantrasyonları 2 katına çıkartılarak sırasıyla, 1, 2 ve 1 mg/L'e yükseltilmiştir. TC, CTC ve PCT'nin 2 katına çıkartılmasına rağmen bu periyotta denitrifikasyona önemli ölçüde tesir etmediği görülmüştür. Ayrıca bu periyotta sodyum asetat konsantrasyonu $0.6 \mathrm{mg} / \mathrm{L}$ 'e yükseltilmiştir.

P5'te elde edilen denitrifikasyon verimi TC/PCT etkisinde ve CTC/PCT etkisinde \%98.8 olmuştur. P6'da anaerobik hidrolik bekleme zamanı 5 saate düşürülerek denitrifikasyon veriminde biraz düşüş yaşanmıştır. Bu şartta elde edilen denitrifikasyon verimi yaklaşık TC/PCT ve CTC/PCT için sırasıyla \%96.8 ve \%92.4 olmuştur. CTC/PCT ikilisinin TC/PCT iklisine göre denitrifikasyon üzerine etkisi daha fazla olmuştur. P7'de Parasetamol $5 \mathrm{mg} / \mathrm{L}$ 'e çıkarılmasına rağmen denitrifikasyon verimi TC/PCT ve CTC/PCT etkisinde \%99.1 olarak elde edilmiştir. Bu şartta TC ve CTC sabit tutulmuştur. P8'de Parasetamol konsantrasyonu 100mg/L'e çıkartılmış olup, denitrifikasyon verimi önemli derecede etkilenerek TC/PCT ve CTC/PCT etkisinde sirasıyla \%79.49 ve \%67.7 olarak elde edilmiştir. P9'da anaerobik fazda parasetemol $500 \mathrm{mg} / \mathrm{L}$ civarında beslenmiş olup denitrifkasyon verimi TC/PCT ve CTC/PCT etkisinde \%0.7 civarında elde edilmiştir. Parasetamolün anaerobik fazda beslenmesi denitrifkasyonun tamamen bitmesini sağlamıştır.

Şekil 4 TC/PCT ve CTC/PCT ikilisinin denitrifikasyonda oluşan $\mathrm{NO}_{2}-\mathrm{N}$ konsantrasyonunu gösteriyor. Şekil incelendiğinde TC/PCT etkisindeki nitrit oluşumu CTC/PCT etkisindekinden bazen fazla bazen de az olarak kararsız davranmıştır. P1'de TC/PCT ve CTC/PCT etkisindeki nitrit konsantrasyonları sirasıyla, 0.96 ve $0.88 \mathrm{mg} / \mathrm{L}$ olmuştur.

P1'de nitritin yüksek olması sistemin başlangıç şartı olmasından kaynaklanmıştır. P2'de nitrit oluşumu giderek azalmış olup, TC/PCT ve CTC/PCT için $0.17 \mathrm{mg} / \mathrm{L}$ olmuştur. P3, P4 ve P5 de nitrit oluşumu stabilleşmiş, TC/PCT ve CTC/PCT için sırasıyla, $0.11,0.19$ ve 0.055 olmuştur. P6'da anerobik hidrolik bekleme zamanı 5 saate düşürüldüğünde TC/PCT ve CTC/PCT etkisinde nitrit oluşumu her ikili için $0.014 \mathrm{mg} / \mathrm{L}$ olmuştur. P7'de de nitrit oluşumu düşük olup $0.018 \mathrm{mg} / \mathrm{L}$ olmuştur.P8'deki TC/PCT ve CTC/PCT etkisindeki nitirt oluşumu sırasıyla, 0.07 ve $0.7 \mathrm{mg} / \mathrm{L}$ olmuştur

P9'da ise bu oran $0.125 \mathrm{mg} / \mathrm{L}$ olmuştur. Şekil genel olarak incelendiğinde TC, PCT ve CTC konsantrasyonlarının artması nitrit oluşumunu önemli derecede etkilemediği anlaşılmıştır. 


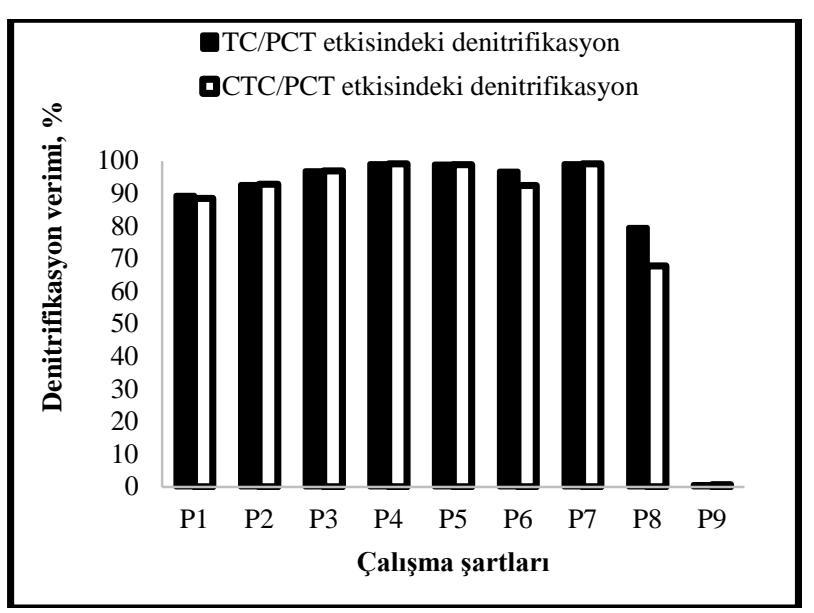

Şekil 3.Tetrasiklin/Parasetamol ve Klortetrasiklin/Para setamol ikilisinin denitrifikasyon üzerine etkisi

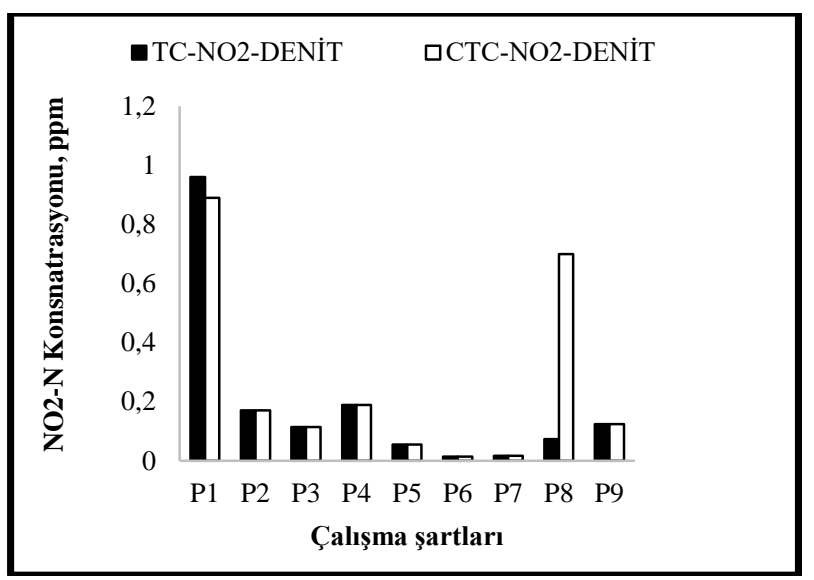

Şekil 4. Tetrasiklin/Parasetamol ve Klortetrasiklin/para cetemol ikilisinin nitrit oluşumu üzerine etkisi

\section{Sonuçlar}

Çalışmadan çıkarılan önemli sonuçlar aşağıda sıralanmıştır.

1. Hem nitrifikasyon hem de denitrifikasyonda CTC/PCT ikilisi TC/PCT ikilisine nazaran daha toksik etki oluşturmuştur.

2. $100 \mathrm{mg} / \mathrm{L}$ 'e kadar Parasetamol nitrifikasyon ve denitrifikasyon üzerine önemli derecede toksik etki oluşturmamıştır.

3. SBR sistemlerinde 3 saatin alltındaki hidrolik bekletme süresi bu tür kirleticilerin olduğu nitrifikasyon ve denitrifikasyonda azotlu bileşiklerin dönüştürülmesinde uygun olmadığı görülmüştür.

4. $500 \mathrm{mg} / \mathrm{L}$ Parasetamol nitrifikasyonda $\% 36$ verim elde edilmesine sebep olurken, denitrifikasyonda \%1'lere düşmüştür.

5. Denitrifiye bakterilerin nitrifiye bakterilerine nazaran farmasotiklere karşı daha hassas olduğu belirlenmiştir.

\section{Çıkar çatışması}

Yazar, çıkar çatışması olmadığını beyan etmektedir.

\section{Benzerlik oranı (iThenticate): $\% 7$}

\section{Kaynaklar}

[1] I. Sirés Sadornil, Electrochemical advanced oxidation processes for the removal of the drugs paracetamol, clofibric acid and chlorophene from waters. Universitat de Barcelona, 2007.

[2] G. Chen, J. Ye, H. Bao, P. Yang, Determination of the rate constants and activation energy of acetaminophen hydrolysis by capillary electrophoresis. J.Pharm. Biomed. Anal. 29, 843-850, 2002. https://doi.org/ 10.1016/S0731-7085(02)00211-X

[3] C. Yan, Y. Yang, J. Zhou, M. Liu, M. Nie, H. Shi, and L. Gu, Antibiotics in the surface water of the Yangtze Estuary: Occurrence, distribution and risk assessment. Environ. Pollut. 175, 22-29, 2013. https://doi.org/ 10.1016/j.envpol.2012.12.008

[4] J. P. Bound, and N. Voulvoulis, Pharmaceuticals in the aquatic environment - a comparison of risk assessment strategies, Chemosphere 56, 1143-1155, 2004. https://doi.org/10.1016/j.chemosphere.2004. 05.010

[5] K. Kummerer, Antibiotics in the aquatic environment - A review - Part II. Chemosphere 75, 435-441, 2009. https://doi.org/10.1016/j.chemosphere.2008.12.006

[6] Ş. Sayg1, D. Battal ve N. Ö. Şahin, Çevre ve insan sağlığı yönünden ilaç atıklarının önemi, Marmara Pharmaceutical Journal, 16, 82-90, 2002. https://doi.org/10.12991/201216406

[7] A. Septian, S. Oh, and W. S. Shin, Sorption of antibiotics onto montmorillonite and kaolinite: competition modelling. Environmental Technology, 40, 22, 2940-2953, 2019. https://doi.org/10.1080/ 09593330.2018 .1459870

[8] M. J. Ahmed, Adsorption of quinolone, tetracycline, and penicillin antibiotics from aqueous solution using activated carbons: Review. Environmental Toxicology and Pharmacology, 50, 1-10, 2017. https://doi.org/10.1016/j.etap.2017.01.004

[9] H. Koch, A. H. Maartje, J. van Kessel, and S. Lücker, Complete nitrification: insights into the ecophysiology of comammox Nitrospira. Applied Microbiology and Biotechnology, 103, 177-189, 2019. https://doi.org/ 10.1007/s00253-018-9486-3

[10] M. H. Ward, T. M. de Kok, P. Levallois, J. Brender, G. Gulis, B. T. Nolan, and J. VanDerslice, Work group report: drinking water nitrate and health Recent findings and research needs. Environ. Health Perspect, 113, 1607-1614, 2005. https://doi.org/10.1289/ ehp.8043.

[11] S. Fields, Global nitrogen: Cycling out of control. Environ. Health Perspect, 112, A556-A563, 2009.

[12] J. Y. Park and Y. J. Yoo, Biological nitrate removal in industrial wastewater treatment: Which electron donor we can choose. Appl.Microbiol.Biotechnol, 82, 415429, https://doi.org/10.1007/s00253-008-1799-1 2009.

[13] M. T. Oğuz, Investigation of nitrifying bacterial activities by monitoring nitrite oxidation, nitrate 
formation and carbon dioxide fixation during activated sludge treatment in the presence of metabolic inhibitors allylthiourea and azide. Erciyes Üniversitesi Fen Bilimleri Enstitüsü Dergisi, 21 (1-2), 154-165, 2005.

[14] S. Mace and J. Mata-Alvarez, Utilization of SBR technology for wastewater treatment: An Overview, Ind. Eng. Chem. Res., 41, 5539-5553, 2002. https://doi.org/10.1021/ie0201821

[15] R. L. Irvine, P. A. Wilderer, and H. C. Flemming, Controlled unsteady-state processes An overview. Water Sci. Technol., 1997, 35 (1), 1, 1997. https://doi.org/10.1016/S0273-1223(96)00872-4
[16] M. Singh, and R. K. Srivastava, Sequencing batch reactor technology for biological wastewater treatment: A review. Asia-Pacific Journal of Chemical Engineering, 6, 3-13, 2011. https://doi.org/10.1002 /apj.490

[17] D. Scaglione, G. Tornotti, A. Teli, E. Ficara, R. Canziani, and F. Malpei, Nitrification denitrification via nitrite in a pilot-scale SBR treating the liquid fraction of co-digested piggery/poultry manure and agro-wastes. Chemical Engineering Journal, 228, 935-943, 2013. https://doi.org/10.1016/j.cej. 2013.05.075 